\title{
Comentarios
}

\section{Un necesario cambio de marcha en El Salvador}

El impacto de los terremotos del 13 de enero y del 13 de febrero impone el desafío de efectuar una serie de cambios al modo cómo se ha venido gestionando el país en las últimas décadas. Todo parece indicar que se está fraguando, entre los diversos sectores socio-políticos, un cierto consenso en torno a esa necesidad. El gobierno, al hacerse cargo públicamente —al menos dentro del paísde las tesis del documento Elementos para la reconstrucción y el desarrollo de El Salvador. Una contribución desde la sociedad civil, elaborado por la Comisión Nacional de Desarrollo, está avalando, queriéndolo o no, la elaboración y búsqueda de propuestas de reforma económica, social y medioam- biental para El Salvador. Más aun, en una línea estrictamente oficial, el gobierno ha asumido expresamente el desafío del cambio, tal como se colige de la lectura del documento Unidos por El Salvador. Plan de recuperación de los daños causados por los terremotos del 13 de enero y 13 de febrero de 2001 , presentado por la comisión gubernamental ente la Reunión del Grupo Consultivo de Madrid (7 de marzo de 2001)'. En una dirección no tan oficial, pero con una influencia indudable en las posturas gubernamentales, la Comisión Económica para América Latina y el Caribe (CEPAL), con su estudio El terremoto del 13 de enero de 2001 en El Salvador. Impacto socioeconómico y am-

1. En efecto, pese a que internamente se vendió la idea -con una presentación en el Hotel Princes incluida- de que la comisión gubernamental que sc presentaba ante cl Grupo Consultivo de Madrid, el 7 de marzo de 2001, iba a apoyarse en el documento Elementos para la reconstrucción y el desarrollo de El Salvador -elaborado por la Comisión Nacional de Desarrollo, a pedido del presidente Francisco Flores-, desde el 5 de febrero se tuvo noticias de otro informe titulado Unidos por El Salvador, cl cual rccogía la posición oficial en torno al impacto del terremoto del 13 de enero. Al parecer, este último documento, divulgado en la página de Internet del Banco Interamericano de Desarrollo (BID), con su título completo, Unidos por El Salvador. Plan de recuperación de los daños causados por los terremotos del 13 de enero y 13 de febrero de 2001 - y calzado con cl escudo nacional de El Salvador, a continuación de lo cual se puede leer: Reunión del Grupo Consultivo. Coordinada por el Banco Interamericano de Desarrollo. Madrid, España. Marzo 7 de 2001-, fue el que respaldó a la comisión gubcrnamental en su visila a Madrid. Es claro, al comparar Unidos por El Salvador con Elementos para la reconstrucción... que se trata de dos documentos distintos, tanto en contenidos como en la filosofía que los inspira. En otras palabras, que el documento de la Comisión Nacional de Desarrollo no fue el texto oficial, pese a que como informara, el 17 de febrero, La Prensa Gráfica, en los preparativos para ir a Madrid, el presidente Flores había decidido encargar un documento a la Comisión Nacional de Desarrollo, descartando el que antes había pedido a dos de sus ministros y a un ejecutivo bancario - para más señas: el propio Daboub, Migucl Lacayo, Ministro de Economía, Claudio de Rosa, director cjecutivo de ABANSA - ¿Fue cste último documento el que al final decidió presentar el gobierno, dejando de lado el de la Comisión Nacional de Desarrollo? Quién sabe qué sucedió; cosas de la política criolla. 
biental $^{2}$ ha abundado en la urgencia de impulsar una serie de reformas al modo cómo se ha venido gestionando el país, en las últimas décadas. Finalmente, tomando distancia de lo que pueda asociarse con los fines del gobierno, se sitúa el FMLN, con su iniciativa titulada Estrategia de reconstrucción y de transición al desarrollo, que también pretende aportar lo suyo para contribuir a los cambios necesarios en el país.

La Comisión Nacional de Desarrollo dice claramente que su documento constituye "el inicio de un proceso de diálogo que tendrá que desarrollarse en las próximas semanas para incluir a otros actores sociales y para precisar propuestas que contribuyan al diseño y a la ejecución de los planes de reconstrucción social". Siendo así las cosas, no puede menos que tomársele la palabra a la Comisión Nacional de Desarrollo y contribuir a que el diálogo iniciado tenga continuidad, de modo que mediante el mismo se vayan perfilando de manera más clara lanto los problemas fundamentales del país como sus posibles vías de solución.

Ante todo, es necesario iniciar la discusión - tal como es la tónica en prácticamente todos los documentos mencionados- examinando cuál era la siluación de El Salvador antes de los dos terremotos. Aquí vamos a seguir nuestra propia argumenlación, no sin antes señalar que algunas de las preocupaciones apuntadas en estas páginas también eslán planteadas en las contribuciones de la CEPAL, la Comisión Nacional de Desarrollo y el FMLN. Sin embargo, no se trala de una repelición (o un plagio) de lo que ahí se dice, sino más bien de una coincidencia surgida del interés comparlido por construir un país más justo y solidario. Asimismo, hay claros puntos de distanciamiento entre la propuesta que esbozaremos en estas páginas y las propuestas elaboradas en los documentos aludidos. Se trata de un distanciamiento en aspectos sustanciales, tanto en la caracterización de los problemas más graves del país como en la sugerencia de los mecanismos más adecuados para hacerles frentc.

Una primera característica de esa siluación es la desarticulación estructural entre sus tres cjes económicos fundamentales, es decir, entre la agricultura, la industria y el sector financiero. Del deterioro del sector agricola se ha hablado hasta la saciedad, al igual que del rezago del aparato industrial. También se ha insistido en la expansión del sector financiero, expansión que ha llevado a la concentración de millonarias sumas en manos de las familias que controlan los bancos, las compañías de seguros y las empresas de pensiones. Aquí conviene insistir en que la expansión del sector financiero ha sido a costa de los otros dos sectores económicos, ahogados por las deudas, las altas tasas de interés, la ausencia de inversiones y el at raso tecnológico.

En segundo lugar, vinculado a lo anterior, está la precariedad social, que afecla a la mayor parte de la población. Esta precariedad guarda una estrecha relación con la incapacidad del aparato productivo para generar niveles adecuados de empleo, tanto en términos de puestos de trabajo como en términos de salarios, acordes con las necesidades básicas de los salvadoreños. Desempleo, subempleo y salarios bajos se traducen en dificultades permanentes para acceder a una vivienda digna y segura, así como a niveles adecuados de salud y educación.

En tercer lugar, se tiene el complejo problema de la violencia social, en sus diversas expresiones: crimen organizado, delincuencia común y violencia cotidiana de lodo lipo. Quizás sea demasiado alirmar que la violencia es resultado directo de la precariedad social y la pobreza, pero lo que no pucde ponerse en duda es que ambas son caldo de cultivo para el malestar y la agresividad sociales.

En quinto lugar, se tiene el problema de la ruptura entre la sociedad, la política y el aparato estatal. Esta ruptura consiste en que las demandas sociales no encuentran la intermediación requerida en el sistema político, mientras que, por su lado, el Eslado no liene la capacidad ni los recursos idóncos para atender las demandas sociales fundamentales. Es por este "fracaso de la política" que se abren en el país las puertas al desencanto, a la apatía y, en situaciones extremas, a la protesta violenta de quienes no encuentran eco estatal a sus demandas.

Finalmente, un uso "desordenado" de los recursos naturales y del espacio territorial. Las manifestaciones más notorias de cllo son, por un lado, la lógica que predomina en la construcción de viviendas urbanas (aunque lambićn rurales) y, por oro, la cultura generalizada del abuso sobre los re-

2. La CEPAL ya ha publicado un adéndum al documento de cvaluación del primer terremolo. Fl segundo informe se litula El Salvador: evaluación del terremoto del martes 1.3 de febrero de 200I. México, 1.3 de febrero de 2001. 
cursos naturales. Se tiene que insistir en algo: el uso "desordenado" de los recursos naturales y del espacio territorial no lo es por descuido o ignorancia (aunque lambién haya algo de eso), sino por un lógica depredadora que, alimentada por el afán de ganancias a cualquier precio, va arrasando con todo lo que encuentra a su paso, sean personas o recursos naturales. Estamos, pues, ante un desorden, gobernado por un cierto "orden": el impuesto por la voracidad empresarial y la incompetencia estatal.

Si se leen los mapas de El Salvador, elaborados por la Comisión Nacional de Desarrollo, a la luz de esa lógica -ma-

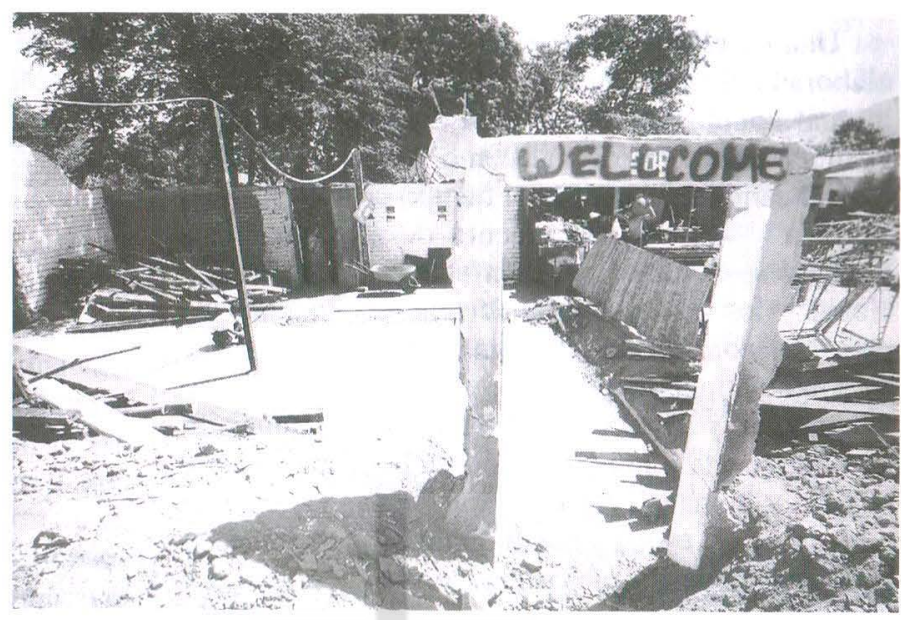
pas que presentan, de manera gráfica, la distribución territorial de la población, la pobreza, las empresas, la recudación fiscal y la inversión pública-', resulta claro que es un país ordenado, a parlir de la explotación abusiva de su población y sus recursos, en decir, un país ordenado en función de los intereses de unas elites empresariales, que lo ven como una gran hacienda, de la cual hay que extraer riquezas a como dé lugar.

Los anteriores son los ejes que han caracterizado al país hasta antes del 1.3 de enero. La pregunta que hay que hacerse es la siguiente: ¿cómo es que llegó a configurarse un pais con las caracteristicas descritas?

Una primera respuesta puede ser que fue por voluntad divina. Emparentada con ella, puede darse la respuesta de que fue por imposición de la naturaleza, con sus leyes inexorables. Ambas ideas son sumamente peligrosas, puesto que pueden traducirse en un peligroso falalismo acerca de lo que le espera a El Salvador y acerca de lo que se puede hacer para cambiar un ordenamiento social. económico y medioambiental excluyente de la mayor parte de la población y depredador de los recursos naturales.

Más bien, dejando para una discusión posterior tanto el complejo tema de la "voluntad divina" como el no menos complejo tema de la "inexorabilidad de la naturaleza", se puede proponer una respuesta a la anterior interrogante que permita hacer algo para cambiar el ordenamiento socio-económico y medioambiental prevaleciente en el país. La

respuesta aludida es la siguiente: El Salvador llegó a configurarse con las características antes apuntadas debido a una inadecuada gestión económica, social y medioambiental.

Esta gestión, que se podría calificar de "tradicional", ha girado en torno a los siguientes ejes: (a) Jébil e incliciente entramado institucional. Ello ha dado pie tanto a la discrecionalidad en la toma de decisiones como a la corrupción en la estructura del Estado; $(b)$ voracidad empresarial que no ha conocido límites y que se hat traducido en una explotación creciente de la fucrza de trabajo y de los recursos naturales; (c) fracaso de la clase política en su función de intermediación socio-política, Io cual ha dado lugar a brotes de descontento social, que amenazan la estabilidad del país; $(d)$ politicas públicas centralizadas y burocráticas, que no sólo han sido ineficaces para responder a las necesidades ciudadanas, sino que además han estado orientadas casi exclusivamente a favorecer a determinados grupos de poder económico; (e) bajos niveles de organizacion y participación sociales, que han llevado a la mayor parte de la población a ser mero receptor pasivo de las decisiones emanadas del aparato estatal, muchas veces bajo la presión de la gran empresa privada.

Si algo no puede ponerse en duda es que los ierremolos sacaron a luz estas debilidades en la gestión económico-social y medioambiental vigente en el pais. Su impacto plantea la necesidad y la oportunidad de un cambio en la misma. ¿Cuáles son las opciones que se presentan?

3. Ver Comisión Nacional de Desarrollo, acciones te'ritoriale's del plan de nacioin, 21 de noviembre de 2000. 
Una de ellas es, como ya dijimos, la propuesta elaborada por la Comisión Nacional de Desarrollo, la cual apunta, ante todo, a la descentralización y al ordenamiento territorial como mecanismos clave para el cambio. "Ahora es el tiempo de la descentralización" - dice el documento de la mencionada Comisión-. "La articulación entre el gobiemo nacional y los gobiemos municipales es un requisito para la reconstrucción". Asimismo, "la reconstrucción debe impulsarse con una visión de ordenamiento territorial y de reorganización política-administrativa que tienda a la integración de la geografía económica y humana". Una vez que se avance en esta dirección, se estará en condiciones para avanzar hacia los siguientes ejes de la "visión de regiones y desarrollo productivo": la ampliación y reconversión de la clase empresarial y la integración centroamericana y mundial. Los actores de esta "transformación social" son, en su orden, el gobiemo nacional, los gobiemos municipales, la empresa privada —a la que tienen que ofrecérsele los incentivos y las facilidades necesarias - y la sociedad civil.

Una segunda iniciativa es la diseñada directamente por el gobierno, la cual está asociada con la anterior, no tanto a perspectiva o contenidos, sino en cuanto al auspicio gubernamental del cual ambas gozan. La propuesta gubernamental, en resumen, viene a decir lo siguiente: el país eslaba bien hasta el 12 de enero - marchaba por la senda de la democracia y el desarrollo socioeconómico-, pero los dos terremotos han quebrado esa buena marcha de El Salvador. De lo que se trata es de relomar el camino que se traía, para lo cual es necesaria la cooperación financiera internacional.

La evolución "lineal" del país comenzó en la década de los años noventa, con la firma de la paz. "Se inició un ejemplar proceso de reconciliación. Paralelamente, El Salvador emprendió un proceso de reforma educativa, ampliación de los servicios de salud, reconstrucción de su infraestructura... Como parte de su desarrollo político, El Salvador impulsa varios mecanismos para crear espacios y estructuras de participación y consulta a la sociedad civil en la gestión de los asuntos públicos, operando varios esquemas, tanto en el nivel nacional como en el nivel local". En consonancia con ello, el documento Unidos por El Salvador, le apuesta a una "recupera- ción" de lo que se tenía, en materia social, económica y política, hasta antes del 13 de enero.

La tercera iniciativa, abanderada por el FMLN, tiene como meta la creación de una "nueva sociedad", a partir de una "revolución moral", "necesaria para enfrentar la emergencia y para contrarrestar y superar el egoísmo, el endiosamiento del dinero a costa del hambre de los demás, los cuales son anti-valores para el ser humano, propios del capitalismo". El partido de izquierda no oculta el deseo de que su Estrategia de reconstrucción se convierta en punto de partida para la edificación de una "nueva sociedad", cuyos gestores principales son, en su orden, el FMLN, los trabajadores y los campesinos y una gama de sectores sociales (¿subordinados a los tres primeros?) que va desde las mujeres, los integrantes de las redes locales y los gobiernos locales hasta los salvadoreños en el extranjero y los gobiernos amigos, pasando por iglesias, militares y empresarios patriotas, pequeños y medianos empresarios y empresas extranjeras.

Para el FMLN, a diferencia del gobierno, el país estaba de lo peor antes de los dos terremotos del año 2001; se trata, entonces, de aprovechar la situación de desastre para avanzar hacia un "nuevo modelo" de sociedad que sustituya "el modelo de acumulación actual que es excluyente y antepone sobre los intereses de la persona humana, de la comunidad y del medio ambiente la ganancia del capital, en un proceso destructivo".

La cuarta propuesta es la de la CEPAL. De lejos, su documento es uno de los más completos sobre el impacto del terremoto del 1.3 de enero, aunque buena parte de su relevancia estriba en la abundante masa de datos que presentat. El estudio de la CEPAL no se detiene en la consideración de cómo estaba el país antes del terremoto, salvo en dos rubros: la situación ambiental —marcada por la expansión de la frontera agrícola, la deforestación, la degradación de los suclos, el agotamiento de las fuentes de agua y la ausencia de tratamiento de las aguas residuales y en la disposición y eliminación de desechos sólidos en las áreas urbanas y rurales- y la situación macroeconómica — de la cual se resaltan el crecimiento en 2 por ciento del PIB para el año $20(0)$, el deterioro de las finanzas públicas en relación a 1999, un déficit fiscal del go-

4. De hecho, de sus 115 páginas, unas 80 recogen información cxhaustiva sobre los daños provocados por cl primer terremoto. Mientras tanto, desde la página I0) 3 hasta la 115 se aborda el importante tema de la reconstrucción. 
biemo central del 2.3 por ciento del PIB, el crecimiento de los sectores transporte y comunicaciones (6.2 por ciento), bancos y seguros (5.1 por ciento) e industria manufacturera (4.5 por ciento), los déficit comerciales compensados por las remesas y la inflación, que mostró para el año 2000 una variación cercana al 4.3 por ciento, revirtiendo la deflación ( -1 por ciento) registrada en 1999 -

Con este trasfondo medioambiental y macroeconómico $-y$ considerando el impacto del terremoto del 13 de enero-, la CEPAL lanza el desafío de elaborar una estrategia nacional de reconstrucción, la cual "es responsabilidad nacional". Se insiste en el componente de "mitigación de riesgos", que conduzca a unas condiciones socioeconómicas de menor vulnerabilidad social, pero tal estrategia debe ponerse en continuidad con la marcha que traía el país hasta el 12 de enero. "La definición nacional de las propuestas de rehabilitación y reconstrucción - se puede leer en el documento cepalino- ha de darse a la luz de las prioridades del país, los objetivos generales de tipo social y económico vigentes antes del terremoto, y la evolución económica previa al desastre, en particular en la zona afectada".

Como puede verse, se tienen cuatro propuestas de muy distinto carácter. Al revisarlas, queda claro que la más polémica es la del FMLN. En efecto, el partido de izquierda abandera una postura amarrada a un enfoque ideológico que, irremediablemente, hará que las élites empresariales —soliviantadas por las empresas mediáticas más poderosas- se pongan a la defensiva ante la posibilidad de cualquier cambio, por mínimo que sea. Ya se han alzado en contra de la propuesta efemelenista las voces de El Diario de Hoy, temerosas, ahora como en décadas pasadas, de cualquier iniciativa que se haga bajo la inspiración de cualquier fórmula socialista. La sola palabra "socialista" enerva y provoca agudos dolores estomacales a quienes han hecho del anticomunismo un estilo de vida.

De las otras tres, la más técnica es la de la CEPAL. Lástima que ese bagaje de información se encuentre "contaminado" por un marco interpretalivo de la dinámica del país coincidente con la interpretación que ofrece el gobierno en su Unidos por El Salvador. El problema no está en la coincidencia en sí misma, sino en que la CEPAL hace suya ( ¿o promueve?) una interpretación sumamente discutible de la dinámica del país. No cuestionar los objetivos económicos y sociales vigentes antes del terremoto - peor aún, plantear que el reto es insertar la reconstrucción en el marco de esos objetivos- no sólo es hacerle el juego al gobierno, sino cerrar las puertas a la posibilidad de superar las graves deficiencias en la gestión socioeconómica y medioambiental de El Salvador.

Algo parecido puede decirse de la propuesta de la Comisión Nacional de Desarrollo: señala graves problemas estructurales - pobreza, deterioro del medioambiente, concentración del gasto público, pésimo ordenamiento territorial-, pero no dice cómo fue que el país llegó a configurarse de ese modo. Por tanto, ofrece una solución -descentralización y ordenamiento territorial, reconversión de la clase empresarial e integración centroamericana y mundial - que, aunque importante, deja intactos los ejes del poder, económico y político, que contribuyeron a configurar el pais que ahora tenemos. La Comisión Nacional de Desarrollo señala varios de los lastres estructurales de El Salvador; sin embargo, olvida decir que el país no llegó a tal situación por descuido, ignorancia o mala voluntad. Ha habido mucho de las tres cosas, pero también ha existido la decisión firme de explotar a sus gentes y recursos, la voluntad de construir un pais en beneficio de unos pocos y la oposición a cualquier cambio en el orden vigente, incluso al precio del asesinato.

Con todo, de todas las propuestas examinadas, la más cuestionable es la del gobierno. Quizás sea mucho pedir objetividad a unos tecnócratas acorralados en las trampas de la publicidad. Sin embargo, un poco de decencia si se les puede y debe exigir. Insistir en las bondades del país, cuando lo que campea es la pobreza, la marginalidad, la corrupción, la debilidad de las instituciones y el fracaso de la clase política, es una burda manipulación de la realidad. Pretender que lo ideal es continuar con el rumbo que traía El Salvador antes de los terremotos es cerrar los ojos ante las debilidades de ese modelo de país. Precisamente, lo que hicieron los terremotos fue poner en evidencia esas debilidades, algunas de las cuales han sido señaladas prrcisamente por la Comisión Nacional de Desarrollo, tanto en su último documento como en las Bases para el plan de nación y en Acciones territoriales para el plan de nación.

5. Ver Centro de Información, Documentación y Apoyo a la Investigación (CIDAI), "Evaluación crítica de las Bascs para cl plan de nación", ECA 594 (abril de 1998) 295-318. 
La discusión seguida hasta ahora impone como conclusión ineludible que El Salvador no puede seguir como hasta ahora ni en lo socioeconómico ni en lo político ni en lo medioambiental. Son tales los niveles de deterioro del tejido social, vulnerabilidad, marginalidad socioeconómica de una buena parte de la población, fracaso de las instituciones y violencia, que continuar en la ruta que se traía antes de los terremolos es aceptar que los males apuntados o no tienen solución o son lo que se merece una sociedad acostumbrada al abuso, la prepotencia y el maltrato de quienes concentran la riqueza y de quienes regentan el aparato del Estado.

Como quiera que sea, más allá de las discusiones ideológicas, el país urge de cambios que vayan más allá de la descentralización, el ordenamiento territorial y la mitigación de riesgos - con todo lo importante ello pueda ser-. Asimismo, estos cambios, aunque drásticos en algunas áreas, no tienen por qué inscribirse en un horizonte socialista o revolucionario. Simplemente, basta con una buena dosis de sentido común y de racionalidad para entender que El Salvador no puede continuar como hasta ahora, pues de seguir tal cual, las tan preciadas riquezas se verán amenazadas, como en el pasado, por desbordes sociales que darán al traste con las mejores expectativas.

¿Cuáles pueden ser los ejes básicos de un nuevo modelo de gestión - económica, social, política y medioambiental- para El Salvador? A modo de propuesta tentativa, se pueden apuntar los siguientes elementos: $(a)$ ese nuevo modelo de gestión debe contribuir a $-y$ apoyarse en- una reforma en la estructura de la propiedad (empresas, bancos y tierras agrícolas); (b) debe articular al sector financiero con la agricultura y la industria, fomentando las inversiones de mediano y largo plazo, en esos sectores productivos; $(c)$ debe apoyarse en un sólido entramado institucional, que ponga límites a la discrecionalidad, al abuso y a la corrupción; $(d)$ debe concretarse en un conjunto de políticas públicas, diseñadas para atender los desafíos de un país amenazado por "riesgos" naturales, económicos y sociales; (e) debe dar paso a una "cultura del riesgo y de la seguridad", que supon- ga para todos los habitantes hacer lo que se pueda para no ser una "amenaza" para los demás, al tiempo que permila trabajar para erradicar las amenazas de tipo natural, social y económico existentes; $(\delta)$ debe fomentar la organización y la participación sociales - con toda la diversidad de opciones y demandas que las caracteriza-, con miras a potenciar las energías colectivas en el ámbito local; y $(g)$ debe contribuir a una renovación de la clase política, sin la cual las posibilidades de cambio en el país se verán obstaculizadas por las inercias y los vicios de unos partidos y líderes que no tienen más propósito que salvaguardar sus propios intereses.

Los cambios en El Salvador deben inscribirse en el marco de los desafíos que plantea la era de la información y la globalización. En ese contexto, tanto los movimientos sociales $\longrightarrow$ dicho de otra forma, la organización y participación activa de la sociedad en la discusión y solución de los problemas más urgentes- como las instituciones políticas desempeñan una función de primera importancia en la potenciación del cambio social. En palabras de Manuel Castells, "los partidos políticos [...] han agotado su potencial como agentes autónomos del cambio social, atrapados en la lógica de la política informacional y cuando su principal plataforma, las instiluciones del Estado-nación han perdido gran parte de su importancia. Sin embargo, siguen siendo instrumentos esenciales para procesar las demandas de la sociedad, encabezadas por los movimientos sociales, en el ámbito de la política nacional, internacional y supranacional. En efecto, aunque los movimientos sociales son los que tendrán que proveer los nuevos códigos bajo los cuales pueden repensarse las sociedades y restablecerse partidos políticos de algún tipo [...] los partidos siguen siendo entidades cruciales para institucionalizar la transformación social. Son negociadores influyentes más que innovadores poderosos".

Luis Armando González Director del Centro de Información, Documentación y Apoyo a la Investigación de la UCA San Salvador, 15 de marzo de 2001.

6. M. Castells, La Era de la información. Economia, sociedad y cultura. Vol. 2. El poder de la identidad. Madrid, 1998, p. 400. 